\title{
O SABER MÉdICO E A UTOPIA HIGIÊNICA NO CONTEXTO LUSO-BRASILEIRO $(1750-1800)^{1}$
}

\section{Jean Luiz Neves Abreu}

Universidade Federal de Uberlândia

\section{Resumo}

A partir de tratados e memórias de medicina, esse artigo busca compreender o olhar médico produzido sobre as cidades entre metade do século XVIII e início do XIX. Procura-se discutir as relações entre os fundamentos científicos da medicina e a constituição de um discurso de cunho higiênico produzido sobre o espaço urbano, bem como os sentidos que o saber médico relativo essa questão assumiu no contexto lusobrasileiro.

Palavras-chave: Cidade, higiene, medicina luso-brasileira

\section{Abstract:}

From medical textbooks and memories, this article seeks to understand the medical gaze produced about cities in the middle of the eighteenth and early nineteenth centuries. It seeks to discuss relations between the scientific foundations of medicine and the constitution of a hygienic stamp discourse produced on the urban space, as well as the directions of medical knowledge concerning this issue made in the context Luso-Brazilian.

Key-words: City, hygiene, Luso-Brazilian medicine.

Ao longo do século XVIII as cidades passam a ocupar cada vez mais um lugar central na elaboração do saber médico. Michel Foucault, ao se deter sobre saber médico nesse contexto, observou que as epidemias levaram a uma inflexão da medicina, passando de uma análise dos sintomas, para a observação do lugar e do momento em que se manifestavam. O que levou a uma nova totalização do olhar médico, fundado nas topografias (situação dos lugares, do terreno, do ar, da sociedade) e nas observações meteorológicas. Esse olhar produziu uma intervenção

\footnotetext{
${ }^{1}$ Esse artigo é parte de uma pesquisa mais ampla relacionada às práticas científicas no século XVIII e vincula-se a dois projetos em andamento: "Divulgação de saberes e práticas científicas na América Portuguesa- século XVIII", (financiado pela PROPP- Pró-reitoria de Pesquisa e Pósgraduação - UFU) e "Religião, Natureza e Costumes: gestos, saberes e discursos na América portuguesa (século XVIII)", na qual atuo como colaborador (financiado pelo CNPq).
} 
coercitiva, expressa no controle do comércio, regulamentação de matadouros, vigilância sobre cemitérios e locais insalubres (FOUCAULT, 2001: 26-27).

A "medicina urbana" nasce, portanto, da mobilização dos médicos que se voltaram para o exame dos fatores específicos que poderiam levar à proliferação de doenças (CAPONI, 2002: 162, VIGARELLO, 1996: 159-172; FOUCAULT, 1989:89-90). Foi nesse cenário do crescimento demográfico e urbano que se constituiu uma política sanitária expressa pelo termo "polícia médica", doutrina para proteger os homens contra as doenças sociais provocadas pelo abandono de estado de natureza a serviço da saúde coletiva dos citadinos (FAURE, 1997:1997).

Tais questões, embora assumindo feições específicas, não estiveram ausentes dos textos médicos no mundo luso-brasileiro. O propósito aqui é compreender os sentidos assumidos pelo discurso médico relativo ao espaço urbano em Portugal e na América Portuguesa entre as décadas de 1750 e 1800. Para tanto, privilegiamos a análise das ideias de Antônio Ribeiro Sanches e de outros médicos que escreveram nesse período, tomando como referência o Reformismo Ilustrado e suas influências nesses escritos.

Em um primeiro momento, vou me deter nas concepções de Ribeiro Sanches, em particular nas incorporadas ao Tratado da conservação da saúde dos povos (1757), obra que pode ser vista como precursora de uma série de textos que elegem como questões a higiene e a salubridade urbana. Em seguida, procuro fazer uma leitura de textos relativos à América Portuguesa, indicando suas possíveis afinidades com as perspectivas adotadas por Sanches.

\section{Da conservação da saúde dos povos}

Antônio Nunes Ribeiro Sanches nasceu em 1699 e deixou Coimbra na sua juventude, em 1719, formando-se em medicina na Universidade de Salamanca. Sentia-se então oprimido pelo ambiente intelectual dominado pelos jesuítas e pela sua origem judaica. Denunciado por um primo de ser praticante de ritos judaicos, Ribeiro Sanches deixou de vez Portugal em 1726, temeroso em relação à Inquisição que perseguia sua família. Com o intuito de aprofundar seus estudos, esteve em vários países, como Inglaterra e França. Em 1730, foi para a Universidade de Leiden, na Holanda, onde se estabeleceu por alguns anos e manteve contato com o renomado médico Boerhaave, seu principal preceptor. A partir da indicação de Boerhaave dirigiu- 
se para a Rússia, onde exerceu atividade médica durante vários anos, retornando a Paris em 1747 (SANCHES, 1922:8-85).

Em contato com a ciência praticada no restante da Europa e crítico da situação em que se encontrava o saber científico em Portugal, Ribeiro Sanches se tornou um apologista da difusão da ciência moderna no Reino em substituição à orientação escolástica, até então vigente no ensino. Nas Cartas sobre a educação da mocidade, publicada em Paris, em 1760, e enviada ao Diretor Geral de Estudos, o Principal Almeida, o letrado expunha a debilidade da educação em Portugal, tratando, em particular, da defasagem da medicina lusa. Observava que o sistema pedagógico vigente não era "suficiente para educarem os súditos de que tem necessidade o Reino, porque nestas quatro faculdades não entra a ciência natural" (SANCHES, 1922: 159).

Mesmo distante de Portugal, ele manteve contato com homens ilustres e influentes, como D. Luís da Cunha, embaixador em Haia na época, que havia solicitado a Ribeiro Sanches, em 1730, um plano de estudos para ser introduzido na Universidade de Coimbra. Os laços com o embaixador permitiram a Sanches um intercâmbio regular com os elementos próximos da corte de Lisboa e possibilitou a divulgação em Portugal de suas propostas de reformas. Após 1746, trocou várias correspondências com o clérigo Luís Antônio Verney, autor do Verdadeiro método de estudar (1746). Com o médico Jacob de Castro Sarmento, tradutor do Novo Organon, manteve igualmente amplo diálogo epistolar, tendo por objeto a troca de ideias sobre o progresso das ciências e as atividades da Sociedade Real de Londres e da Academia Real de Paris (ARAÚjO, 1984).

Ribeiro Sanches foi autor de vários textos em que propunha mudanças vistas como necessárias à renovação científica em terras lusitanas e seus domínios. No Tratado da conservação e saúde dos povos, impresso em Paris em 1755 e em Lisboa em 1757, dizia que tinha o desejo de satisfazer o desejo de ser útil a terra onde nasceu. Embora nunca tenha retornado a Portugal, ele é considerado pela historiografia portuguesa como um dos precursores do Reformismo Ilustrado, pela influência de suas concepções na renovação do conhecimento científico e na reforma da Universidade de Coimbra, (CARVALHO, 1987; ARAÚJO, 1984).

Essa breve apresentação do percurso intelectual de Ribeiro Sanches é útil para mostrar os canais de difusão do conhecimento científico em Portugal no século XVIII e seu papel enquanto "estrangeirado" na valorização de um conhecimento fundado no 
experimentalismo e em sintonia com a medicina praticada na Europa do Norte (CARNEIRO, SIMÕES, DIOGO, 2000).

Para os propósitos deste estudo importa salientar que Ribeiro Sanches foi um dos primeiros a sistematizar várias questões ligadas às relações entre a saúde e as cidades, expressa no já mencionado Tratado da conservação da saúde doso povos. Conforme salientam João Rui Pita e Ana Leonor Pereira, a publicação desse texto foi um "dos primeiros indicadores de preocupações higienistas em moldes médicopolíticos". A obra expressava "perspectiva iluminista de saúde pública, tornando-a como uma questão em que a normatividade médica deve atingir os indivíduos através do poder político" (PEREIRA e PITA, 1993: 454).

Ao longo do compêndio, Ribeiro Sanches recorre a várias teorias e concepções que associavam a ocorrência de doenças à insalubridade do espaço urbano, atribuída não só a sujeira das ruas, mas também à qualidade da água e do ar e às características das edificações. A discussão sobre a qualidade do ar respirado pela população ocupa várias páginas do compêndio. Fazendo referências aos avanços da química, o médico observava que "entra o ar no bofe a cada inspiração e serve a conservar e prolongar a vida e a saúde". Segundo expunha, o ar encerrado e úmido encontrava-se cheio de partículas podres. Privado de sua vitalidade, ele tornava-se corrupto, sobrevindo "aquelas ânsias mortais, aquele cansaço, aquele querer respirar e não poder, aquelas pungentes dores de cabeça, aquelas náuseas sem poder vomitar". Era ainda a razão de inúmeras doenças, como o escorbuto e as febres pestilentas (SANCHES, 1757:46-47).

A discussão acerca das influências do ar sobre a saúde dos indivíduos tem suas raízes na tradição hipocrática e remonta ao texto Ares, águas e lugares, que já estabelecia um nexo entre a saúde e o ar que se respirava (AYRES, 2001). Embora faça referência aos textos hipocráticos, ao mencionar as propriedades do ar Ribeiro Sanches tem como referência a obra de Stephen Hales, cujo nome é mencionado diversas vezes. No século XVIII, a publicação dos textos de Hales demonstrara como o ar agia de várias formas sobre os organismos vivos. Em meio à diversidade das teorias da física e da química em torno desse elemento, havia concordância de que o ar era um "caldo pavoroso" no qual se misturavam fumaças, enxofres, vapores e os "miasmas contagiosos". Com base nesse pensamento "aerista" é que se constituem em grande parte as definições do salubre e do insalubre nos séculos XVIII e XIX (CORBIN, 1987:19-22). 
Nesse sentido, o termo "miasma" era utilizado para designar a infecção causada pela putrefação das matérias orgânicas que alteravam o ar ambiente. Diferente da teoria do contágio - segundo a qual a doença era produzida por uma causa específica - os adeptos dessa teoria defendiam que a doença podia se propagar de um indivíduo doente a outro saudável, já que o primeiro podia alterar o ambiente em que se encontravam (CHALHOUB, 1996:169). Antes da noção de que as enfermidades eram transmitidas pelo contágio se constituir como paradigma com a denominada "Revolução pausteriana", a noção de infecção por "miasma" encontrava respaldo científico nos meios médicos. ${ }^{2}$

Em diálogo com essas teorias, Ribeiro Sanches discorre sobre os fatores responsáveis pela transformação da qualidade do ar, tais como as variações climáticas, os ventos, as exalações dos rios e a putrefação dos organismos mortos. 0 médico atenta para a especificidade das regiões dos trópicos, como as possessões portuguesas em Moçambique, Angola e Brasil. Nestes sítios onde o calor e a umidade eram contínuos, o que concorria para a podridão da atmosfera e inúmeras enfermidades, pela providência divina também se gerava toda a sorte de aromas e especiarias atenuando os efeitos perniciosos do ar corrompido (SANCHES, 1757:43).

Com base em tais pressupostos, Ribeiro Sanches propunha que os médicos fossem consultados pelos magistrados e arquitetos para a fundação de cidades. Desde o início, evidenciam-se as finalidades políticas de sua obra: o autor considera que em Portugal tais conhecimentos viriam a ser úteis, pois em seus "dilatados domínios" inúmeras povoações eram fundadas e a escolha dos sítios mais sadios para as edificações urbanas poderia salvar a vida de seus vassalos. O sítio mais apropriado era aquele direcionado para o oriente, com águas correntes e pelas quais pudessem entrar embarcações e que fosse ventilado pelo vento frio. Mas se, por "razões de Estado", fosse necessário escolher lugares que não tivesse tais condições, a arte deveria suprir os defeitos da natureza (SANCHES, 1757:61-67).

Esses conselhos não se alicerçavam somente nas concepções científicas do século XVIII. Na parte dedicada à reforma das cidades, Sanches faz menção em especial ao arquiteto renascentista Leon Batista Alberti: "Leão Baptista Alberti pode ser o mais judicioso autor nesta matéria, diz que uma cidade terá toda a dignidade e

\footnotetext{
${ }^{2}$ Sobre a noção de cientificidade, seguindo a perspectiva de Flávio Edler, cabe observar que a moderna historiografia das ciências não se pode tomar como conceitos e metodologias que hoje consideramos válidas para determinado campo de conhecimento para julgar as práticas científicas do passado. Antes do advento da bacteriologia predominavam questões epistemológicas distintas (EDLER, 2009:155)
} 
formosura se se fundar em sítio mediocremente levantado" devendo-se, para tanto, investigar as qualidades do terreno e "bondade das águas" (SANCHES, 1757:70). O médico extraía tais ideias do De Re Aedificatoria (1450), onde Alberti ensinava a corrigir o clima, os odores locais e evitar as enfermidades, em acordo com o paisagismo e as medidas sanitárias adequadas à saúde dos habitantes (BRANDÃO, 2000:254).

Quanto às práticas saneadores, há igualmente referências a recursos para combater os maus odores utilizados bem antes do século XVIII e que se perpetuaram até o início do século XIX. É o caso da utilização de substâncias aromáticas. No século XVII, o médico João Ferreira da Rosa indicava como forma de combater a peste que assolava Pernambuco lançar à fogueira "ramos de murta, ou bálsamo, ou óleo de copaúba, ramos de aroeira, erva-cidreira", adicionando nas casas outras coisas aromáticas "como rosas, sândalos, tragacanto, bejoim, romaninho, alecrim, estoraque, mirta, almíscar". Defendia que com isso se fazia "o ar mais puro, e cheiroso, e os seminários de contágio se consomem" (ROSA, 1956: 264). Ribeiro Sanches igualmente fazia referência a uns "pós para purificar o ar corrupto" composto de substâncias aromáticas, como rena de pinho, cominhos, bagas de zimbro, incenso, entre outros ingredientes (SANCHES, 1757: 163). Embora não explicassem a qualidade do ar pela influência dos astros, como fazia João Ferreira da Rosa, os médicos do setecentos ainda buscavam justificar cientificamente a virtude terapêutica de certos arômatas, na busca de anti-sépticos capazes de combater a ação dos miasmas pútridos (CORBIN, 1987:87).

Se Ribeiro Sanches inspira-se no passado, sua cidade ganha contornos utópicos ao se filiar, por exemplo, às idéias de Francis Bacon, o qual em sua Nova Atlântida previa a existência de instrumentos para purificar o ar: "Temos também certas câmaras a que chamamos de câmaras de saúde, nas quais regulamos o ar do modo considerado bom e adequado á cura de diversas doenças e à restauração da saúde" (BACON, 1979:264).

Apesar dessas referências, as medidas propostas por Ribeiro Sanches para sanear as cidades estavam em sintonia com a medicina de sua época. Nesse sentido, aconselhava aos magistrados sobre a necessidade de determinadas reformas, como haver "em cada cidade, vila ou lugar, lei inviolável que cada morador tivesse de limpar pela manhã a fronteira da sua casa". Recomendava igualmente a utilização de certo número de carros para transporte das lamas e imundícies. Na cidade idealizada pelo médico não seria admissível nenhum "ofício que causasse podridão ou mau 
cheiro", de tal forma que os carniceiros, curtidores, vendedores de peixe e queijos viveriam em locais afastados (SANCHES, 1757: 79-80). Nesses aspectos, as propostas de Ribeiro Sanches estavam em acordo com as estratégias sanitárias aplicadas em cidades como Paris desde meados do século XVIII, em que desinfetar e desodorizar faziam parte de um projeto utópico que visava "calar os testemunhos do tempo orgânico" (CORBIN, 1987: 126).

Além da atenção despendida à higiene das cidades, cabia também melhorar as edificações onde se concentrava grande número de pessoas, como os hospitais e prisões. No Tratado da conservação da saúde dos povos, um capítulo específico foi dedicado ao "Sumo cuidado que se deve ter nas prisões para purificar o ar delas e renová-lo cada dia". A renovação do ar incluía soluções que associavam o saber médico às técnicas disponíveis na época, como o recurso aos instrumentos de ventilação para purificar o ambiente dos hospitais. (SANCHES, 1757:170).

Ao tratar dos hospitais, o médico propunha várias medidas para evitar a proliferação das doenças e a transmissão das enfermidades pelo ar corrompido. Neste ponto o discurso médico se coloca como necessário ao da arquitetura, na medida em que para Ribeiro Sanches "todo cuidado deve ter o arquiteto quando edificar o hospital, fazê-lo respirável e areado por todos os lados" (SANCHES, 1757: 154). A obsessão pela purificação do ar se estende a outros espaços, como conventos, igrejas, mosteiros e cemitérios. Postulava o médico: "Se as exalações que saem dos corpos viventes são tão venenosas; que efeitos não produzirão aquelas dos cadáveres que estão apodrecendo" (SANCHES, 1757: 121)

Ribeiro Sanches se detinha sobre tudo o que nas vilas pudessem resultar em enfermidades e epidemias. A publicação de seu tratado sobre a saúde dos povos em Portugal (1757) ganha relevância se considerarmos que o texto veio a público dois anos após o terremoto que assolou a cidade de Lisboa, em 1755 (DEL PRIORE, 2003). Mas foi somente nas últimas décadas do século XVIII que a questão da higiene urbana mereceu atenção dos governantes e foi alvo de uma organização sanitária mais efetiva. Destaca-se, nesse aspecto, a atuação de Pina Manique, Intendente Geral da Polícia da Corte de D. Maria, nomeado para esse cargo em 1780. O Intendente mobilizou recursos empregados na limpeza das ruas, hospitais e prisões e na criação de cemitérios públicos, em combate aos sepultamentos no interior das igrejas. Dentre suas medidas, ele proibiu às pessoas de lançar animais mortos no Tejo e criou um sistema de limpeza pública, tendo em vista tornar Lisboa uma cidade equiparada às outras capitais da Europa (PINTO, 1990:39). 
A transição do século XVIII para o XIX representou um momento significativo de reflexão acerca da higiene e da salubridade em Portugal, nos meios rurais e, principalmente, nos centros urbanos (CRESPO, 1990: 218-219).

Em 1818, a publicação do Tratado de polícia médica, de autoria de José de Freitas Soares, sistematizava uma série de discussões sobre a higiene urbana já presentes na obra de Sanches. Freitas Soares ressaltava a importância da correção do ar dos hospitais, "sendo o asseio uma circunstância essencial" para que isso fosse possível. Além disso, propugnava também que nas cidades houvesse lugares para aqueles que vendiam os "miúdos" dos animais mortos, pois eles exalavam "vapores nocivos à saúde pública" (SOARES, 1818: 121).

Conforme observa João Rui Pita, a noção de "polícia médica" revela o significado político e social que assume a higienização. Todo um conjunto de comportamentos, de rituais e de instituições, como cadeias e hospitais, passam a ser tratados sob esse prisma. Assim, a higiene médica do início dos oitocentos não abandona o "sonho de uma cidade física e moralmente perfeita" (PEREIRA e PITA, 1993:470).

Entre a publicação do compêndio escrito por Sanches e o tratado de Freitas Soares, várias textos de medicina publicados em Portugal e circularam na América Portuguesa. Tais textos, ao mesmo tempo em que contribuíam para divulgar as teorias que fundamentavam o discurso higienista, reivindicavam uma racionalização do olhar médico sobre as cidades.

Atendendo ao princípio da utilidade e da conservação da saúde, memórias, artigos em periódicos e manuais traziam à tona diversas causalidades para as enfermidades que atingiam os habitantes não só em Portugal, como nos seus domínios. Esses textos estabeleciam, ainda que de forma indireta, um diálogo com as propostas de Ribeiro Sanches, mas também incorporavam determinadas mudanças.

\section{Cidades e miasmas na América Portuguesa}

Não se pode perder de vista a relação entre a produção de saberes sobre o mundo urbano no contexto em Portugal e a condição colonial. Dessa maneira, esses textos podem ser interpretados como produto de um ethos português ultramarino e se vinculam à experiência vivenciada na América Portuguesa.

Como já comentado, o próprio Ribeiro Sanches fez questão de observar as condições climáticas dos territórios sob domínio lusitano como um elemento a ser 
considerado na edificação dos núcleos urbanos. Em várias passagens, ele se reporta aos "sítios" da América Portuguesa e aos obstáculos para a edificação de centros administrativos e outras construções. Menciona as inundações dos rios, como o São Francisco, as quais geravam "exalações podres" na atmosfera, provendo febres pestilentas e outras moléstias. A essas causas se somavam ainda o calor e a umidade dos trópicos (SANCHES, 1757: 37-40)

As ressalvas feitas por Ribeiro Sanches acerca das condições nosológicas da Colônia puderam ser verificadas in loco pelo cirurgião Antônio José de Araújo Braga. Formado em Coimbra e tendo exercido cirurgia nos hospitais de Cadiz, Évora e no Hospital Real de São José de Lisboa, ao ser nomeado para exercer a função de "cirurgião da gente de guerra da diligência da demarcação dos limites", constatou que as muitas enfermidades que acometiam os habitantes do Pará e das margens do rio Negro procediam dos "miasmas podres de que a atmosfera se acha carregada" e do calor da atmosfera quente e úmida (OBSERVAÇÕES MÉDICAS DE ANTÔNIO ARAÚJO BRAGA, 1983: 745-749).

Parte de um relatório encomendado pelo naturalista Alexandre Rodrigues Ferreira, o relato do cirurgião pode ser associado com a política pombalina de povoamento e a criação de vilas em regiões como Mato Grosso e Goiás, planejadas por engenheiros militares e cartógrafos. À sombra das cidades planejadas, antigas vilas coloniais como Salvador e Rio de Janeiro eram consideradas insalubres. A tendência comum às memórias de medicina dessa época era a de associar as enfermidades com as condições urbanas, fosse pela qualidade da água, das exalações, fosse pela construção de casas sem ventilação (NIZZA DA SILVA, 1999:71-80).

Além disso, as considerações de Araújo Braga, assim como as de Sanches, reforçavam a percepção negativa sobre as regiões tropicais recorrente na literatura setecentista e que podem ser situadas no âmbito das polêmicas em torno do Novo Mundo, difundidas por autores como Buffon e Montesquieu que viam a América sob o signo da inferioridade (GERBI, 1996). A "invenção dos trópicos" a partir da expansão ultramarina trouxe, ao lado da visão paradisíaca, representações negativas que se convertem em lugares comuns na literatura de viagem do século XVIII. A literatura médica desse período sobre a África ocidental e o Caribe reforçou as imagens do clima inclemente e das enfermidades que acometiam os colonos de forma violenta (ARNOLD, 2000:138-139). Se nas cidades europeias as pestes e as febres eram imputadas às condições de insalubridade das cidades, no caso das regiões situadas 
nos trópicos a esses fatores se acrescentavam ainda às qualidades do clima, visto como mais propenso à produção de miasmas corruptos.

Os textos traziam à tona problemas mais específicos relativos aos trópicos, como a qualidade do ar respirado na cidade. A esse respeito, destaca-se a memória de José Pinto de Azeredo, publicada no Jornal Enciclopédico. Natural da América Portuguesa, após freqüentar as universidades de Edimburgo e Leiden e obter, em 1789, carta que o autorizava a exercer medicina em Portugal e seus domínios, Azeredo veio para o Rio de Janeiro onde exerceu atividade clínica naquele mesmo ano (PITA, 2005: 624-638).

No período de sua estadia naquela cidade, realizou um estudo que consistia no exame químico da atmosfera do Rio de Janeiro. Segundo informava, em decorrência das descobertas da ciência moderna e da química, tornava-se possível examinar mais profundamente a atmosfera, de modo a distinguir a qualidade de três tipos de ar e seus efeitos diversos no organismo: o ar puro, o ar fixo e o ar mofete, de natureza praticamente desconhecida. ${ }^{3}$ Após estudar a composição da atmosfera do Rio de Janeiro e realizar experiências em determinados locais, como no centro e na Misericórdia, concluía que naquela atmosfera havia menos ar puro e mais ar mofete. Cogitava se não era aquele ar "atraindo os vapores maus das lagoas, e águas encharcadas, ainda servindo de alimentos a certos insetos (...) a causa condutora das enfermidades" (JORNAL ENCICLOPÉDICO, 1790: 259-285).

Pinto Azeredo identificava o ar mofete com o "ar corrupto" de Lavoisier, fazendo outras referências à teoria do químico. Em um de seus escritos, Memórias sobre o ar e a água, Lavoisier observava que dos fenômenos da "economia animal" a que mais merecia atenção era a respiração. Era preciso diferenciar os "ares" próprios e impróprios para a respiração, sendo o espaço que contivesse ar mefítico e limitado de oxigênio considerado mortal (MAZZOLINI, 1997:112; CAPONI, 2002, 165).

José Pinto de Azeredo toma como ponto de partida a ideia em voga entre os médicos que associa as enfermidades à qualidade do ar, mas o faz com base em experiências que permitem indicar variações na composição atmosférica do Rio de Janeiro e incorpora as teorias de Lavoisier difundidas após 1760 . Se por um lado, as reflexões médicas da Ilustração se fundamentam em teorias que podem ser

\footnotetext{
${ }^{3}$ A nomenclatura utilizada por Azeredo para designar as qualidades dos ares corresponde à utilizada na química de fins do século XVIII. O ar puro correspondia ao oxigênio, o ar fixo, ao dióxido de carbono, e o ar mofete uma composição em que entrava o azoto, designava o nitrogênio. Para uma análise mais detalhada da experiência realizada por José Pinto de Azeredo e de sua trajetória consultar Cf. (PITA et AL, 2005 : 617-673).
} 
denominadas neo-hipocráticas; por outro lado, é possível perceber inflexões desse conhecimento médico nas últimas décadas do século XVIII. Tais mudanças são perceptíveis nos estudos sobre especificidade de cada clima e lugar, referendadas pelas experiências científicas e pela observação dos dados meteorológicos, topográficos, geográficos e culturais conformadas nas "topografias médicas" (KURY, 2007:157-160).

Importa também chamar atenção para a relevância do estudo de José Pinto de Azeredo, pois em 1798 a Câmara da cidade propôs questões sobre as doenças endêmicas e epidêmicas que grassavam na capital. A resposta a esse inquérito foi publicada no jornal $O$ Patriota por três médicos, Manoel Joaquim Marreiros, Bernardino Antônio Gomes e Antonio Joaquim de Medeiros. Os três concordavam serem as condições climáticas da cidade, caracterizadas pelo calor, umidade e pestífero ar, responsáveis pelas enfermidades. A esses fatores se juntavam outros, como os tipos de construção, falta de escoamento e esgotos, sujeira, dentre outros fatores que poderiam ser remediados pelas autoridades públicas com medidas de reordenamento urbano (KURY, 2007:161-164).

Importando teorias e conceitos que acabavam por reforçar a depreciação da natureza americana, os médicos luso-brasileiros colocavam em xeque a própria dificuldade de se estabelecer uma civilização nos trópicos, problema agravado pelas condições insalubres nas cidades, sendo poucas as excessões a esse diagnóstico pessimista. É o caso do naturalista Arruda da Câmara, o qual dizia que a pátria natural dos seres humanos era próxima aos trópicos, destinados pela sua natureza para a habitação dos homens (KURY, 2004: 123-124).

Além desses aspectos, o saber médico se confrontou com antigas sensibilidades bastante arraigadas nos costumes das populações coloniais, como a de enterrar os mortos dentro das igrejas ou em sua proximidade. Em razão do perigo dos "miasmas" exalados pelas sepulturas, essa prática passou a ser cada vez mais objeto de condenação médica. As medidas de intervenção nos cemitérios em locais sagrados propiciaram convulsões sociais no século XIX, como exemplifica o caso da "cemiterada" na Bahia, movimento em que as irmandades se sublevaram contra a lei proibitiva dos enterros no interior das igrejas (REIS, 1992).

Apesar de no Brasil intervenções dessa natureza datarem do oitocentos, a questão dos cemitérios é herdeira das preocupações higienistas do século XVIII (CORBIN, 1987:135). A respeito do assunto, o médico Vicente de Seabra Silva Teles publicou, em 1800, pela tipografia do Arco do Cego, Memória sobre os prejuízos 
causados pelas sepulturas dos cadáveres dos templos e methodo de os prevenir. Na memória questionava a razão pela qual os "católicos romanos" fizeram com que os "santos edifícios" das sepulturas fossem impuros e razão de diversas doenças, construindo-os no interior dos templos ou em sua proximidade. Fundamentando-se no princípio da "fermentação", o médico observava que a "emanação pútrida é tão venenosa, que, bem como um fermento podre, é capaz de excitar a podridão nos outros animais de perfeita saúde e causar epidemias" (TELES, 1800:12). Consideravase que os gases formados pela putrefação dos corpos resultavam em terrível veneno para a saúde. Para tais males, os remédios prescritos eram diversos: a destruição dos cadáveres, a construção de cemitérios fora das povoações, extração das terras infeccionadas das sepulturas ou lançar na terra substâncias capazes de neutralizar as emanações podres (TELES, 1800: 22).

Silva Teles demonstrava estar a par dos textos que circulavam na Europa sobre o risco dos cemitérios à saúde. No final da Memória ele menciona que pouco antes de finalizar seu estudo havia tomado conhecimento do Ensaio sobre os lugares e os perigos das sepulturas, de Vicq d'Asyr (TELES, 1800: 35). O texto citado tratava-se de uma tradução da obra do Italiano Scipion Piatoli, Saggio intorno al luogo di seppelire, a qual foi provavelmente a fonte do médico Correia Picanço para escrever seu Ensaio sobre os perigos das sepulturas dentro das cidades e nos seus contornos, em 1812 (REIS, 2004: 271).

Tais aspectos são indicativos de como os letrados em Portugal e na América Portuguesa se apropriavam das teorias médicas do século XVIII e, ao mesmo tempo, revelam como a higiene das cidades passa a ser um tema cada vez mais freqüentado nessa literatura. Textos como o de Silva Teles coadunam com a perspectiva médica iluminista e defesa da razão contra os hábitos tradicionais, fazendo seu autor um elogio os "progressos da filosofia natural" e os recursos que essa prestava às "necessidades sociais" (TELES, 1800:25).

Amparado em argumentos científicos, alguns médicos incorporaram elementos morais ao seu discurso, condenando os locais insalubres, como os prostíbulos. Nessa perspectiva, Francisco de Mello Franco solicitava aos confessores que instruíssem os penitentes que não andassem por "ruas infames", casas de meretrizes e de jogos, e outros lugares onde "se respira um ar pestilento ou infeccionado com exalações que se levantam dos corpos minados de doenças, tais como o gálico, sempre existente nas mulheres lascivas" (FRANCO, 1994:138). 
Em Elementos de higiene, de 1814, Francisco de Melo Franco retomaria o tema, alertando para o perigo do "grande ajuntamento de gente em lugares pouco arejados" e da reunião excessiva de pessoas nos "teatros, nas igrejas, nas prisões e nos hospitais, onde o ar não circulando livremente é alterado pela respiração, e emanações animais, como o provam as observações eudiométricas". Constatava, enfim, que os miasmas dos corpos "atacando os nervos, tendem a aniquilar a vida" (FRANCO, 1814: 45). Embora extrapole o contexto em estudo, a referência a essa obra é relevante para evidenciar a continuidade de um discurso que adentraria o oitocentos (EDLER, 2009).

O mote da higiene servia, portanto, para propor uma reordenação dos corpos nos espaços urbanos, demarcando a diferente entre sãos e doentes; lugares puros e impuros. Prestava-se igualmente de justificativa para a condenação aos lugares vistos como impuros e perigosos. Anuncia ainda o projeto de separar as pessoas visando impedir o efeito das emanações sociais (CORBIN, 1987:133).

\section{Considerações finais}

Sem a pretensão de realizar um inventário de todos os textos médicos relativos à questão urbana, espero ter demonstrado alguns vínculos possíveis de serem estabelecidos entre as teorias "aeristas" e a produção de um conhecimento que se voltava para as cidades no cenário luso-brasileiro desde a metade do século XVIII. Nesse contexto, os médicos em Portugal e na América Portuguesa, representantes da elite letrada, produziram obras que associavam várias enfermidades aos "miasmas"; aos ares corrompidos, exalados das cidades e dos estabelecimentos urbanos, como hospitais, cemitérios e outros locais insalubres.

Formados em acordo com os princípios da ciência moderna aprendidos na Universidade de Coimbra e, em alguns casos, universidades estrangeiras, esses médicos se apropriaram de teorias e questões caras ao discurso médico-higiênico do Iluminismo europeu e procuraram aplicá-los às cidades coloniais, atrelando-as a motivos peculiares como indica a discussão sobre a natureza de uma sociedade estabelecida nos trópicos.

Como já mencionado, esse saber médico se vinculava a questões utilitaristas da preservação da saúde dos povos como "razão de Estado". Dessa maneira, a utopia de 
uma cidade saudável era acompanhada de um ethos ultramarino que conformava o Reformismo Ilustrado Português. Até onde se sabe a produção desse conhecimento destinado à reforma dos espaços urbanos encontrou obstáculos de ordem prática no período abordado. De qualquer maneira, no conjunto desses textos é possível identificar traços de um discurso higienizador que, no século XIX, continuou a vicejar discussões entre os médicos sobre o problema da insalubridade de alguns centros urbanos (KURY, 2008).

\section{Referências}

ARAÚJO, Ana Cristina. Ilustração, pedagogia e ciência em Antônio Nunes Ribeiro Sanches. Revista de História e teoria das idéias.Revoltas e revolução, Coimbra. Faculdade de Letras, Universidade de Coimbra, v. 6, p. 377-395, 1984.

ARNOLD, David (2000). La natureza como problema histórico. El médio, La cultura y La expansión de Europa. México: Fundo de Cultura Económica.

AYRES, José Ricardo de Carvalho Mesquita (2001). A saúde coletiva e o espaço público moderno: raízes histórico-sociais da ciência epidemiológica, Projeto história, São Paulo, n.23, p. 83-103, Nov.

BACON, Francis (1979). Nova Atlântida. São Paulo: Abril Cultural.

BRANDÃO, Carlos Antônio (2000). Quid Tum? O combate da arte em Leon Batista Alberti. Belo Horizonte: Editora UFMG.

CAPONI, Sandra (2002). Miasmas, micróbios y conventillos. Asclepio, v. 54, n.1, p. 155-182.

CARNEIRO, Ana; SIMÕES, Ana. DIOGO; Maria Paula (2000). Enlightenment Science in Portugal: The estrangeirados and their communication networks. Social Studies of Science, 30, 4, p. 591-619.

CARVALHO, Rômulo de (1987). História do ensino em Portugal: desde a fundação da nacionalidade até o fim do regime de Salazar-Caetano. Lisboa: Fundação Calouste Gulbenkian.

CHALHOUB, Sidney (1996). Cidade febril: cortiços e epidemias na corte imperial. São Paulo: Companhia das Letras.

CORBIN, Alain (1987). Saberes e odores: o olfato e o imaginário social nos séculos dezoito e dezenove. São Paulo: Companhia das Letras.

CRESPO, Jorge (1990). A história do corpo. Lisboa: Difel.

DEL PRIORE, Mary (2003). O mal sobre a terra. Uma história do terremoto de Lisboa. Rio de Janeiro: Topbooks.

EDLER, Flávio Coelho (2009). A natureza contra o hábito: a ciência médica no Império. Acervo (Rio de Janeiro), v. 22, p. 153-166. 
Exame químico da atmosfera do Rio de Janeiro, feito por José Pinto de Azeredo, doutor em medicina pela Universidade de Leyde, físico-mor, e professor de medicina do Reino de Angola. Jornal Enciclopédico (1790). Artigo I: História natural, física e química, março, p. 259-285.

FAURE, Olivier (1997). Les Stratégies sanitaires In: GRMEK, M. D. (Dir). Historie de la pensée médicale en Occident 2. De la Renaissance aux Lumières. Paris: Éditions du Seuil, p.279-296.

FOUCAULT, Michel. Microfísica do poder. Rio de Janeiro: Edições Graal (Biblioteca de filosofia e história das ciências, v.7), 1989.

FOUCAULT, Michel. O nascimento da clínica. Rio de Janeiro: Forense Universitária, 2001.

FRANCO, Francisco de Melo (1814). Elementos de higiene ou ditames teoréticos, e práticos para conservar a saúde e prolongar a vida. Lisboa: Typografia da Academia.

FRANCO, Francisco de Melo (1994). Medicina teológica ou Supplica humilde feita aos senhores confessores, e diretores, sobre o modo de proceder com seus penitentes na emenda dos pecados, principalmente na lascívia, cólera e bebedice [1794] São Paulo: Giordano.

GERBI, Antonello (1996). O Novo Mundo: História de uma polêmica (1750-1900). São Paulo: Companhia das Letras.

KURY, Lorelai (2004). Homens de ciência no Brasil: impérios coloniais e circulação de informação (1780-1810). História, Ciências, Saúde - Manguinhos. v.11 (suplemento 1), p. 109-129.

KURY, Lorelai (2007). Descrever a pátria, difundir o saber. In: KURY, Lorelai B.. (Org.). Iluminismo e Império no Brasil: O Patriota (1813-1814). Rio de Janeiro: Fiocruz/Biblioteca Nacional, p.141-178.

KURY, Lorelai (2008). Rio de Janeiro: a cidade e os médicos no período joanino. In: SCOTT, Ana Silvia Volpi; FLECK, Eliane Deckmann (Org.). A Corte no Brasil: população e sociedade no Brasil e em Portugal no início do século XIX. São Leopoldo: Oikos/Unisinos, p. 119-134.

MAZZOLINI, Renato. G (1997). Les lumières de la raison: des systèmes médicaux à I'organologie naturaliste In: GRMEK, Mirko. D. (Dir). Historie de la pensée médicale en Occident 2. De la Renaissance aux Lumières. Paris: Éditions du Seuil, p. 93-115.

NIZZA DA SILVA, Maria Beatriz (1999). A cultura luso-brasileira. Lisboa Editorial Estampa.

Observações médicas de Antônio Araújo Braga (1983) in: FERREIRA, Alexandre Rodrigues. Viagem filosófica ao Rio Negro. Belém: Museu Paraense Emílio Goldi, Fundação Roberto Marinho. 
PEREIRA, Ana Leonor; PITA, João Rui (1993). Liturgia higienista no século XIX.

Pistas para um estudo. Revista de História das Ideias, v.15, p.437-545.

PINTO, José dos santos. Pina Manique e a saúde pública In: PINTO, José dos Santos; TAVARES, Adérito (Orgs.) (1990) Pina Manique: um homem entre duas épocas. Lisboa: Casa Pia de Lisboa, p. 35-47.

PITA, João Rui Et. al. (2005). O médico brasileiro José Pinto de Azeredo (1766-1810) e o exame químico da atmosfera do Rio de Janeiro. História, ciências, saúdeManguinhos, v. 12, n. 13, p. 617-673, set-dez.

REIS, João José (2004). A morte é uma festa: ritos fúnebres e revolta popular no Brasil do século XIX. São Paulo: Companhia das Letras.

ROSA, João Ferreira (1956) Tratado único da constituição pestilencial de Pernambuco In: MORÃO, ROSA e PIMENTA. Notícia dos três primeiros livros em vernáculo sobre a medicina no Brasil. Estudo crítico de Gilberto Osório de Andrade, introduções históricas, interpretações e notas de Eustáquio Duarte, prefácio de Gilberto Freyre. Pernambuco: Arquivo Público Estadual.

SANCHES, Antonio Nunes Ribeiro (1922). Cartas sobre a educação da mocidade [1760]. Coimbra: Imprensa Universitária.

SANCHES, Antônio Ribeiro (1757). Tratado da conservação da saúde dos povos. Lisboa: Officina Joseph Filipe.

SOARES, José P. Freitas (1818). Tratado de polícia médica. No qual se compreendem todas as matérias que podem servir para organizar um regimento de polícia de saúde, para o interior do reino de Portugal. Lisboa: Typographia da Academia Real das Sciencias.

VIGARELLO, Georges (1996). O limpo e o sujo: uma história da higiene corporal. São Paulo: Martins Fontes. 